\title{
Blood pressure, retinopathy and urinary albumin excretion in IDDM: the EURODIAB IDDM Complications Study
}

\author{
J.M.Stephenson ${ }^{1}$, J.H.Fuller ${ }^{1}$, G.-C. Viberti ${ }^{2}$, A.-K. Sjolie ${ }^{3}$, R.Navalesi ${ }^{4}$, the EURODIAB IDDM Complications \\ Study Group \\ ${ }^{1}$ Department of Epidemiology and Public Health, UCL Medical School, London, UK \\ ${ }^{2}$ Metabolic Unit, Guy's Hospital, London, UK \\ ${ }^{3}$ Eye Department, Aarhus University Hospital, Aarhus, Denmark \\ ${ }^{4}$ Unità Operativa di Malattie del Ricambio, Istituto di Clinica Medica II, Pisa, Italy
}

\begin{abstract}
Summary Several studies have shown an association between blood pressure and nephropathy, but few have been large enough to examine whether, or how, this relation is influenced by retinopathy. We have therefore examined the independent relations of blood pressure to urinary albumin excretion and retinopathy in a cross-sectional observational study of over 3000 insulin-dependent diabetic patients (the EURODIAB IDDM Complications Study). The relation of blood pressure to urinary albumin excretion differed strikingly between patients with $(46 \%)$ and without $(54 \%)$ retinopathy. In those with retinopathy, mean urinary albumin excretion rate was normal $(<20 \mu \mathrm{g} / \mathrm{min})$ below median diastolic pressure $(75 \mathrm{~mm} \mathrm{Hg})$ and increased steeply $(p<0.001)$ with blood pressure above this level. However, in patients
\end{abstract}

without retinopathy, mean albumin excretion rate was normal across the range of diastolic pressure. This finding could not be explained by differences in glycaemic control or duration of diabetes between patients with and without retinopathy. These data identify a subgroup of patients whose high risk of nephropathy may reflect abnormal renal vulnerability to mildly raised blood pressure. Retinopathy is a close correlate of this vulnerability. Detection of even mild retinopathy, together with raised blood pressure, may be important in assessing nephropathy risk. [Diabetologia (1995) 38: 599-603]

Key words Insulin-dependent-diabetes mellitus, diabetic nephropathy, diabetic retinopathy, blood pressure, albumin excretion rate.
Insulin-dependent diabetes mellitus (IDDM) is becoming more common in Europe [1] and few patients escape its complications. The great majority can expect to develop retinopathy $[2,3]$, but only about $30 \%$ are at risk of nephropathy $[4,5]$. Duration of diabetes and poor blood glucose control are established risk factors for these complications [6], but leave much of the individual's risk unexplained. Attention has therefore been focused on raised blood pressure as a modifiable risk factor for these complications [7-10]. However, it is not clear wheth-

Received: 20 July 1994 and in revised form: 28 October 1994

Corresponding author: Dr. J.Stephenson, Department of Epidemiology and Public Health, University College London, 1-19 Torrington Place, London WC1E 6BT, UK

Abbreviations: AER, Urinary albumin excretion rate; IDDM, insulin-dependent diabetes mellitus. er, or to what extent, raised blood pressure is related independently to each of these complications. Large numbers of patients are needed to address this question adequately.

Using cross-sectional data from a large random sample of clinic-attending IDDM patients (the EURODIAB IDDM Complications Study), we have examined the association between retinopathy and nephropathy, and the independent relations of blood pressure to retinopathy and urinary albumin excretion.

\section{Subjects and methods}

The EURODIAB IDDM Complications Study is a clinicbased study in 31 European centres designed to explore risk factors for diabetic complications. Patient selection and methods are described in detail elsewhere [11]. In brief, each centre selected a stratified random sample of clinic-attending pa- 
Table 1. Association between retinopathy and albuminuria

\begin{tabular}{|c|c|c|c|c|c|c|c|}
\hline \multirow[b]{2}{*}{$\begin{array}{l}\text { No } \\
\text { retinopathy }\end{array}$} & \multicolumn{2}{|c|}{$\begin{array}{l}\text { Normal AER } \\
<20 \mu \mathrm{g} / \mathrm{min}\end{array}$} & \multicolumn{2}{|c|}{$\begin{array}{l}\text { Microalbuminuria } \\
20-200 \mu \mathrm{g} / \mathrm{min}\end{array}$} & \multicolumn{2}{|c|}{$\begin{array}{l}\text { Macroalbuminuria } \\
>200 \mu \mathrm{g} / \mathrm{min}\end{array}$} & \multirow{2}{*}{$\begin{array}{l}\text { Total } \\
1280\end{array}$} \\
\hline & $\begin{array}{l}1044^{\mathrm{a}} \\
60.9 \%^{\mathrm{c}}\end{array}$ & $81.6 \%^{b}$ & $\begin{array}{l}229^{\mathrm{a}} \\
44.9 \%^{\mathrm{c}}\end{array}$ & $17.9 \%^{\mathrm{b}}$ & $\begin{array}{l}21^{\mathrm{a}} \\
11.5 \%^{\mathrm{c}}\end{array}$ & $1.6 \%^{\mathrm{b}}$ & \\
\hline $\begin{array}{l}\text { Non-proliferative } \\
\text { retinopathy }\end{array}$ & $\begin{array}{l}572^{\mathrm{a}} \\
33.4 \%^{\mathrm{c}}\end{array}$ & $67.2 \%^{\mathrm{b}}$ & $\begin{array}{l}208^{\mathrm{a}} \\
40.8 \%\end{array}$ & $24.6 \%^{\mathrm{b}}$ & $\begin{array}{l}76^{\mathrm{a}} \\
41.8 \%^{\mathrm{c}}\end{array}$ & $9.0 \%^{\mathrm{b}}$ & 844 \\
\hline $\begin{array}{l}\text { Proliferative } \\
\text { retinopathy }\end{array}$ & $\begin{array}{l}96^{\mathrm{a}} \\
5.7 \%^{\mathrm{c}}\end{array}$ & $37.8 \%^{\mathrm{b}}$ & $\begin{array}{l}73^{\mathrm{a}} \\
14.3 \%\end{array}$ & $28.7 \% \mathrm{~b}$ & $\begin{array}{l}85^{\mathrm{a}} \\
46.2 \%^{\mathrm{c}}\end{array}$ & $34.0 \% \mathrm{~b}$ & 254 \\
\hline Total & 1686 & & 510 & & 182 & & 2378 \\
\hline
\end{tabular}

${ }^{\mathrm{a}}$ Number of patients; ${ }^{\mathrm{b}}$ row percent; ${ }^{\mathrm{c}}$ column percent

tients, with IDDM defined as onset of diabetes before the age of 36 years with continuous insulin treatment initiated less than 1 year from diagnosis. The study was comprised of 3250 patients ( $51 \%$ male), but two centres did not measure retinopathy, and some urine samples were not suitable for measurement of albumin excretion on arrival at the central laboratory. Therefore, data were available for analysis of the relation between blood pressure and urinary albumin excretion rate (AER) in 3046 patients, of whom 2378 also had data on retinopathy. Mean (SD) age of patients in the study was 32.7 (10.2) years, and mean duration of diabetes $14.7(9.3)$ years.

Sitting blood pressure was measured to the nearest $2 \mathrm{~mm} \mathrm{Hg}$ with a random zero sphygmomanometer after $5 \mathrm{~min}$ rest, and the mean of two readings used for analysis. AER was measured in a central laboratory [11] from a timed 24-h urine collection after excluding proteinuria due to urinary tract infection. AER was defined as normal below $20 \mu \mathrm{g} / \mathrm{min}$, and raised at or above that level. Raised AER was also categorised as microalbuminuria $(20-200 \mu \mathrm{g} / \mathrm{min})$ or macroalbuminuria $\left(>200 \mu \mathrm{g} / \mathrm{min}\right.$ ). $\mathrm{HbA}_{1 \mathrm{c}}$ was measured by an enzyme immunoassay [12] in a central laboratory (normal range 2.9 to $4.8 \%$ ). Retinopathy was measured by photography of two retinal fields per eye. A single observer graded all retinal photographs by field-by-field, lesion-by-lesion comparison with standard photographs. Proliferative retinopathy was defined as any new vessels, fibrous proliferations, vitreous haemorrhages or photocoagulation scars. Severe background retinopathy was defined as any cotton wool spots, intra-retinal microvascular abnormalities, venous beading or severe haemorrhages/microaneurysms. The remaining retinopathy consisted of non-severe haemorrhages/microaneurysms alone and was defined as mild background retinopathy.

\section{Statistical analysis}

The statistical power to detect relations between key variables, such as blood pressure and AER, within centres was estimated assuming that most centres would recruit 140 patients. This would allow a difference of $14 \%$ in the frequency of macroalbuminuria between patients in the upper and lower halves of blood pressure distribution to be detected, with over $80 \%$ power at $5 \%$ significance, assuming the prevalence of macroalbuminuria in the lower half to be $3 \%$. Pooled data from all centres are presented because the relation between blood pressure and albuminuria was similar in all centres. Ten percent of patients were on antihypertensive treatment. Blood pressure (mean \pm SD) in these patients (systolic $141 \pm 22 \mathrm{~mm} \mathrm{Hg}$, diastolic $84 \pm 12 \mathrm{~mm} \mathrm{Hg}$ ) was considerably higher $(p<0.001)$ than in untreated patients (systolic $119 \pm 16 \mathrm{~mm} \mathrm{Hg}$, diastolic $75 \pm 11 \mathrm{~mm} \mathrm{Hg}$ ). Assuming that the pre-treatment levels of both blood pressure and AER were higher than the levels measured on treatment, exclusion of treated patients would probably lead to underestimation of the strength of the true (without treatment) relation between blood pressure and AER. To avoid such bias, treated patients were included in analyses of the relation between blood pressure and AER.

AER was log transformed before analysis because of its positively skewed distribution. The relation between blood pressure and geometric mean AER is presented for all patients and for groups stratified by retinopathy and glycaemic control. For stratification, glycaemic control was defined as good if $\mathrm{HbA}_{1 c}$ was below $6.7 \%$ (median $\mathrm{HbA}_{1 \mathrm{c}}$ ) and poor if $\mathrm{HbA}_{1 \mathrm{c}}$ was $6.7 \%$ or greater. Blood pressure was treated as a series of discrete (dummy) variables, i.e. each level of diastolic pressure ( $<65 \mathrm{~mm} \mathrm{Hg}, 65-70 \mathrm{~mm} \mathrm{Hg} \mathrm{etc)} \mathrm{was} \mathrm{treated} \mathrm{as} \mathrm{a} \mathrm{separate} \mathrm{vari-}$ able and each individual assigned a score of 0 or 1 on each variable. At each level of blood pressure, mean AER was adjusted for duration of diabetes and/or $\mathrm{HbA}_{1 \mathrm{c}}$ using a least-squares regression model. The adjusted means are the values predicted in the model when the other variables are held at their mean values. Addition of a term for centre had no effect. Other terms were added to see whether the relation of blood pressure to AER differed between strata, e.g. between patients with and without retinopathy (test for interaction). Prevalence of retinopathy in groups defined by blood pressure level $(<65 \mathrm{~mm} \mathrm{Hg}$, $65-75 \mathrm{~mm} \mathrm{Hg}$ etc) was adjusted for $\mathrm{HbA}_{1 \mathrm{c}}$ and duration of diabetes by direct standardisation to the distribution of $\mathrm{HbA}_{1 \mathrm{c}}$ and duration of diabetes in the whole sample.

\section{Results}

Thirty-one percent of patients (95\% confidence interval $30 \%-32 \%)$ had raised AER and $46 \%(44 \%-$ $48 \%$ ) had retinopathy. There was a positive association between degree of retinopathy and level of albuminuria (Table 1). Macroalbuminuria without retinopathy was rare, but retinopathy without nephropathy was not (38\% of patients with proliferative retinopathy had normal AER). In view of this association, the independent relation between blood pressure and each complication was examined after stratifying by the other complication.

The relation between diastolic blood pressure and AER for all patients is shown in Figure 1 (top panel). At diastolic pressure below $80 \mathrm{~mm} \mathrm{Hg}$, there was a shallow, linear increase in AER with blood pressure. Above $80 \mathrm{~mm} \mathrm{Hg}$, AER increased steeply with diastolic pressure. Figure 1 (lower panel) also shows a striking difference $(p<0.001$, test for interac- 

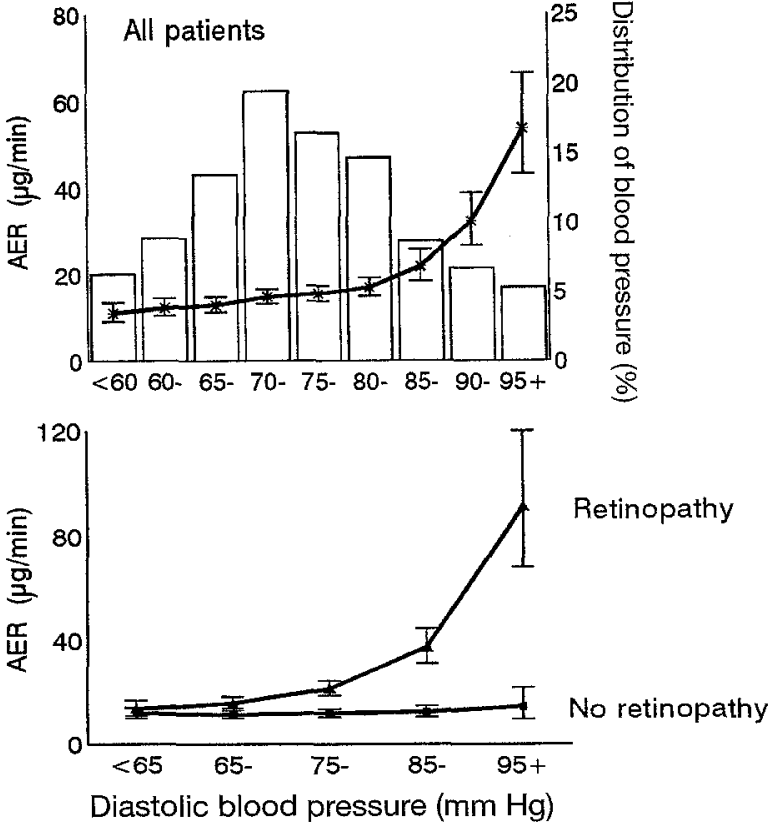

Fig. 1. Geometric mean AER by diastolic blood pressure in all patients (top, $n=3046)$ and in those with $(n=1098)$ and without $(n=1280)$ retinopathy (bottom). Geometric means with $95 \%$ confidence intervals are adjusted for duration of diabetes and $\mathrm{HbA}_{1 \mathrm{c}}$

tion) in the relation of diastolic pressure to AER between patients with and without retinopathy. In patients with retinopathy (lower panel, upper curve), geometric mean AER was normal $(<20 \mu \mathrm{g} / \mathrm{min})$ below median diastolic pressure $(75 \mathrm{~mm} \mathrm{Hg})$ but increased steeply $(p<0.001)$ with blood pressure above this level. But in those without retinopathy (lower panel, lower curve), there was no significant $(p=0.3)$ relation between blood pressure and geometric mean AER which was normal across the range of diastolic pressure. By contrast, over a third of patients with normal AER and low diastolic pressure had retinopathy (Table 2 ). The difference in relation of diastolic pressure to retinopathy between patients with normal and raised AER was of borderline significance ( $p=0.05$, test for interaction). The relation between blood pressure and AER was consistent within centres and sexes; the pattern described

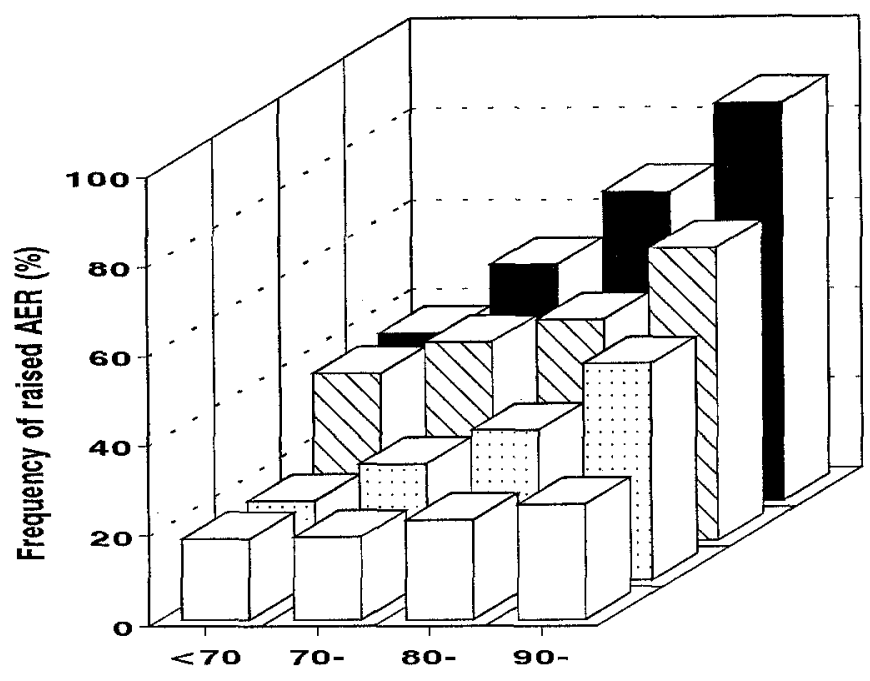

Diastolic blood pressure ( $\mathrm{mmHg}$ )

Fig. 2. Frequency of raised AER by diastolic blood pressure in patients with no retinopathy $(\square)$, mild background $(\because)$, severe background ( and proliferative retinopathy (

above was not confined to certain centres and did not differ appreciably between men and women.

More detailed analysis (Fig. 2) showed a significant increase in frequency of raised AER with blood pressure at each level of retinopathy $(p<0.0001$ for proliferative, $p=0.006$ for severe background and $p<0.0001$ for mild background retinopathy) except none $(p=0.1)$. Figure 2 also allows the strength of the relation between diastolic pressure and AER to be compared between groups with different levels of retinopathy. The increase in frequency of raised AER with blood pressure was more marked ( $p=0.003$, test for interaction) in those with more advanced levels of retinopathy.

Figure 3 shows the relation between blood pressure and AER, stratified by retinopathy and glycaemic control. In patients with no retinopathy, mean AER was normal even when blood pressure was high and glycaemic control poor. In patients with retinopathy, the increase in AER at higher levels of blood pressure was greater ( $p=0.05$, test for interaction) when control was poor.

Table 2. Prevalence of retinopathy by diastolic pressure and level of AER

\begin{tabular}{|c|c|c|c|c|}
\hline \multirow{3}{*}{$\begin{array}{l}\text { Diastolic blood pressure } \\
(\mathrm{mm} \mathrm{Hg})\end{array}$} & \multicolumn{2}{|c|}{ Normal AER $(<20 \mu \mathrm{g} / \mathrm{min})$} & \multicolumn{2}{|c|}{ Raised AER ( $\geq 20 \mu \mathrm{g} / \mathrm{min})$} \\
\hline & \multicolumn{2}{|c|}{ Prevalence of retinopathy } & \multicolumn{2}{|c|}{ Prevalence of retinopathy } \\
\hline & $\begin{array}{l}\text { Crude } \\
(\%)\end{array}$ & $\begin{array}{l}\text { Adjusted }^{\mathrm{a}}(95 \% \mathrm{CI}) \\
(\%)\end{array}$ & $\begin{array}{l}\text { Crude } \\
(\%)\end{array}$ & $\begin{array}{l}\text { Adjusted }{ }^{a}(95 \% \mathrm{CI}) \\
(\%)\end{array}$ \\
\hline $\begin{array}{l}<65 \\
65- \\
75- \\
85- \\
95+\end{array}$ & $\begin{array}{l}33.8 \\
36.1 \\
42.9 \\
42.7 \\
42.5\end{array}$ & $\begin{array}{l}35.2(31.7,38.6) \\
37.1(34.8,39.5) \\
41.1(38.7,43.6) \\
42.7(39.1,46.3) \\
38.0(28.8,47.2)\end{array}$ & $\begin{array}{l}46.8 \\
54.4 \\
63.8 \\
76.6 \\
81.2\end{array}$ & $\begin{array}{l}54.4(47.7,61.0) \\
60.8(56.3,65.3) \\
65.0(61.3,68.7) \\
68.3(63.8,72.9) \\
80.1(73.8,86.5)\end{array}$ \\
\hline
\end{tabular}

${ }^{\mathrm{a}}$ Prevalence of retinopathy adjusted for $\mathrm{HbA}_{1 \mathrm{c}}$ and duration of diabetes. $\mathrm{CI}$, Confidence interval 


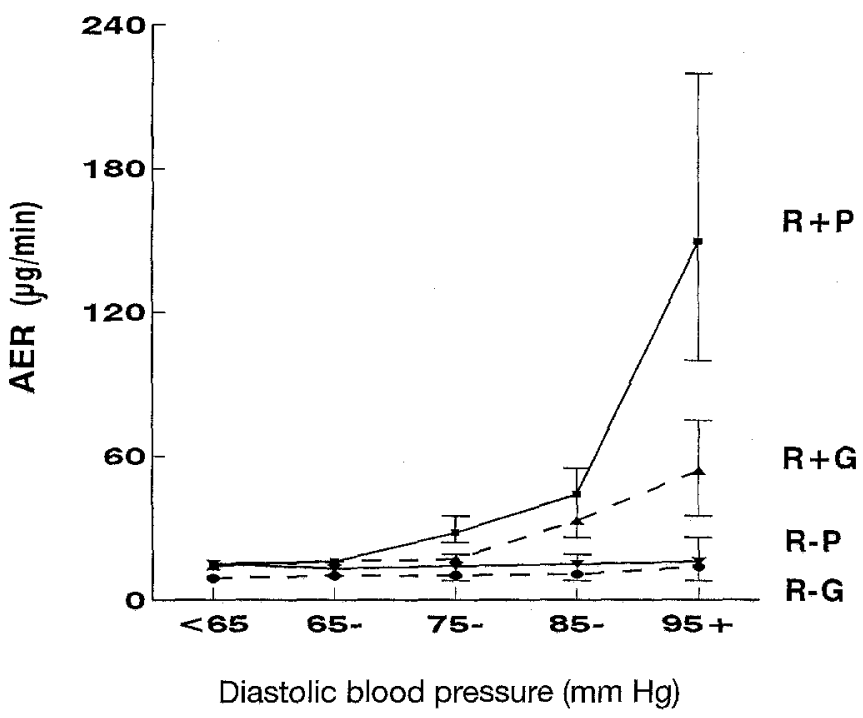

Fig.3. Geometric mean AER by diastolic blood pressure in patients with $(\mathrm{R}+)$ and without $(\mathrm{R}-)$ retinopathy, by good (G) and poor (P) glycaemic control, Geometric means with $95 \%$ confidence intervals are adjusted for duration of diabetes

Findings were similar when relations with AER were analysed with systolic blood pressure in place of diastolic pressure (data not shown).

\section{Discussion}

An association between raised blood pressure and albuminuria in IDDM has been shown in several studies [13-15], but a striking difference in the relation of blood pressure to albumin excretion between patients with and without retinopathy has not been described before. We could not explain this unexpected finding by differences in known risk factors for nephropathy, i.e. glycaemic control and duration of diabetes, between patients with and without retinopathy. The stratified analysis by glycaemic control clearly shows that lack of association between blood pressure and AER in patients without retinopathy was not simply a reflection of better control in these patients. Selection bias in a clinic-based study is an unlikely explanation [11] because clinic attendance would have to depend on a complex interrelation between at least one exposure (blood pressure) and two outcomes (albuminuria and retinopathy).

These data indicate a group of patients whose high risk of nephropathy might reflect increased renal vulnerability to raised blood pressure. Retinopathy is presumably a close marker of this vulnerability. This interpretation assumes that raised albumin excretion is a response to, rather than a cause of, mildly raised blood pressure. Although this sequence of events is still debated [16], our interpretation of this cross-sectional data offers a plausible explanation for the well-recognised association between retinopathy and nephropathy, in which nephropathy without retinopathy is rare but retinopathy without nephropathy is common. The alternative explanation for this association, in terms of blood pressure, is that patients with nephropathy develop retinopathy regardless of blood pressure, while patients without nephropathy only develop retinopathy when blood pressure is high. This clearly does not fit with the common occurrence of retinopathy in patients with normal AER and low blood pressure, nor the weak association between blood pressure and retinopathy in these patients. A stronger association might be expected since hypertension has been linked with increased retinal blood flow and retinopathy $[17,18]$, but other clinical studies [19-21] have not generally found a strong association between hypertension and retinopathy, independent of nephropathy.

We suggest that diastolic blood pressure above $75 \mathrm{~mm} \mathrm{Hg}$ in IDDM patients with even mild, nonsight-threatening retinopathy may be an important indicator of susceptibility to nephropathy. In these patients, poor glycaemic control increases the risk of nephropathy. This interpretation of cross-sectional data needs to be examined prospectively. If confirmed, it should lead to better definition of high-risk patients, in whom intervention might be most effective.

Acknowledgements. We thank all the patients who took part in the study. The study was part of the EURODIAB Concerted Action Programme financially supported by the Commission of the European Communities. Additional financial support was received from ICI UK, Fidia, Bayer, Miles-Ames, Novo Nordisk and Pfizer.

\section{EURODIAB Investigators}

B Karamanos, C Tountas, A Kofinis, K Petrou, N Katsilambros, Hippokration Hospital, Athens, Greece.

R Giorgino, M Cignarelli, ML De Cicco, I Ramunni, Istituto di Clinica Medica, Endocrinologia e Malattie Metaboliche, Universita di Bari, Bari, Italy.

C Ionescu-Tïgoviste, CM Iosif, D Pitei, S Buligescu, Clinic of Diabetes, Nutrition and Metabolic Diseases, Bucharest, Romania.

G Tamas, Z Kerenyi, AM Ahmed, J Toth, P Kempler, Tetenyi Teaching Hospital and Semmelweis University, Budapest, Hungary.

Se Muntoni, M Songini, M Stabilini, M Fossarello, S Pintus, Sä Muntoni, Ospedale San Michele, Cagliari, Italy.

JB Ferriss, CC Cronin, AE Whyte, PE Cleary, Cork Regional Hospital, Cork, Republic of Ireland.

$M$ Toeller, A Klischan, T Forst, FA Gries, Diabetes Forschungsinstitut, and $\mathrm{W}$ Wagener, Medizinische Klinik E, Universitat Dusseldorf, Germany.

R Rottiers, H Priem, University Hospital of Gent, Belgium.

$\mathrm{P}$ Ebeling, M Sinisalo, VA Koivisto, University Hospital of Helsinki, Finland.

B Idzior-Walus, B Solnica, L Szopinska-Ciba, K Solnica, University School of Medicine, Krakow, Poland.

HMJ Krans, HHPJ Lemkes, JJ Jansen, J Brachter, University Hospital of Leiden, The Netherlands. 
J Nunes-Correa, J Boavida, Portuguese Diabetic Association, Lisbon, Portugal.

G Michel, R Wirion, Centre Hospitalier, Luxembourg.

AJM Boulton, H Ashe, DJS Fernando, Manchester Royal Infirmary, UK.

G Pozza, G Slaviero, G Comi, B Fattor, F Bandello, Ospedale San Raffaele, Milan, Italy.

H Mehnert, A Nuber, H Janka, City Hospital Schwabing, Munich, Germany.

D Ben Soussan, M-C Fallas, P Fallas, Centre Hospitalier de Valenciennes, France.

E Jepson, S McHardy-Young, Central Middlesex Hospital, and JH Fuller, DJ Betteridge, M Milne, University College Hospital, London

G Crepaldi, R Nosadini, Istituto di Medicina Interna, Padua, Italy

G Cathelineau, B Villatte Cathelineau, M Jellal, N Grodner, P Gervais Feiss, Hôpital Saint-Louis, Paris, France.

F Santeusanio, G Rosi, MRM Ventura, C Cagini, C Marino, Istituto di Patologia Medica, Policlinico, Perugia, Italy.

R Navalesi, G Penno, R Miccoli, M Nannipieri, S Manfredi, Istituto di Clinica Medica II, Pisa, Italy.

G Ghirlanda, P Cotroneo, A Manto, C Teodonio, A Minnella, Universita Cattolica del Sacro Cuore, Rome, Italy.

JD Ward, S Tesfaye, C Mody, C Rudd, Royal Hallamshire Hospital, Sheffield, UK.

GM Molinatti, F Vitelli, M Porta, GF Pagano, P Cavallo Perin, P Estivi, R Sivieri, Q Carta, G Petraroli, Clinica Medica B, Patologia Medica, Ospedale Molinette, and Ospedale "Agnelli", Turin, Italy.

N Papazoglou, G Manes, G Triantaphyllou, A Ioannides, G Skazagar, I Kontogiannis, General Hospital of 'Thessaloniki, Greece.

M Muggeo, V Cacciatori, F Bellavere, P Galante, ML Gemma, Cattedra di Malattie del Metabolismo, Verona, Italy.

K Irsigler, H Abrahamian, C Gurdet, B Hornlein, C Willinger, Hospital Vienna Lainz, Austria.

S Walford, EV Wardle, S Hughes, New Cross Hospital, Wolverhampton, UK.

G Roglic, Z Resman, Z Metelko, Z Skrabalo, Vuk Vrhovac Institute for Diabetes, Zagreb, Croatia.

Steering Committee Members: JH Fuller (London), H Keen, Chairman (London), HMJ Krans (Leiden), R Navalesi (Pisa), A-K Sjolie (Aarhus), JM Stephenson (London), M Toeller (Dusseldorf), G-C Viberti (London), J Ward (Sheffield).

Co-ordinating Centre: JH Fuller, JM Stephenson, T Partridge, M Milne, UCL Medical School, UK.

Central Laboratories: G John, The Royal London Hospital, and G-C Viberti, M Mattock, A Collins, A Dredge, R Sharp, Guy's Hospital, London, UK.

Retinopathy Co-ordination: A-K Sjolie, Aarhus University Hospital, Denmark.

Retinopathy Grading Centre: E Kohner, S Aldington, S Cockley, Hammersmith Hospital, London, UK.

\section{References}

1. Bingley PJ, Gale EAM (1989) Rising incidence of IDDM in Europe. Diabetes Care 12: 289-295

2. Klein R, Klein BEK, Moss SE, Davis MD, DeMets DL (1984) The Wisconsin Epidemiologic Study of diabetic retinopathy $\Pi$. Prevalence and risk of diabetic retinopathy when age at diagnosis is less than 30 years. Arch Ophthalmol 102: 527-532
3. Orchard TJ, Dorman JS, Maser RE et al. (1990) Prevalence of complications in IDDM by sex and duration. Pittsburgh Epidemiology of Diabetes Complications Study II. Diabetes 39: 1116-1124

4. Andersen AR, Christiansen JS, Andersen JK, Kreiner S, Deckert T (1983) Diabetic nephropathy in tpye 1 (insulindependent) diabetes: an epidemiological study. Diabetologia 25: 496-501

5. Kofoed-Enevoldsen A, Borch-Johnsen K, Kreiner S, Nerup J, Deckert T (1987) Declining incidence of persistent proteinuria in type 1 (insulin-dependent) diabetic patients in Denmark. Diabetes 36: 205-209

6. Wang PH, Lau J, Chalmers TC (1993) Meta-analysis of effects of intensive blood-glucose control on late complications of type 1 diabetes. Lancet 341: 1306-1309

7. Mogensen CE (1989) The effect of blood pressure intervention of renal function in insulin dependent diabetes. Diabete Metab 15: 343-351

8. Nosadini R, Fioretto P, Trevisan R, Crepaldi G (1991) Insulin-dependent diabetes mellitus and hypertension. Diabetes Care 14: 210-219

9. Parving HH (1991) Impact of blood pressure and antihypertensive treatment on incipient and overt nephropathy, retinopathy, and endothelial permeability in diabetes mellitus. Diabetes Care 14: 260-269

10. Janka HU, Ziegler AG, Valsania P, Warram JH, Krolewski AS (1989) Impact of blood pressure on diabetic retinopathy. Diabete Metab 15: 333-337

11. The EURODIAB IDDM Complications Study Group (1994) Microvascular and acute complications in IDDM patients: the EURODIAB IDDM Complications Study. Diabetologia 37: 278-285

12. John GW, Gray MR, Bates DL, Beacham JL (1993) Enzyme immunoassay - a new technique for estimating $\mathrm{HbA}_{1 \mathrm{c}}$. Clin Chem 39: 663-666

13. Parving H-H, Andersen AR, Smidt UM, Oxenbøll B, Edsberg B, Sandahl Christiansen J (1983) Diabetic nephropathy and arterial hypertension. Diabetologia $24: 10-12$

14. Wiseman M, Viberti GC, Mackintosh D, Jarrett RJ, Keen H (1984) Glycaemia, arterial pressure and micro-albuminuria in type 1 (insulin-dependent) diabetes mellitus. Diabetologia 26: 401-405

15. Christensen CK, Mogensen CE (1985) The course of incipient diabetic nephropathy: studies of albumin excretion and blood pressure. Diabet Med 2: 97-102

16. Mogensen CE, Osterby R, Hansen KW, Damsgaard EM (1992) Blood pressure elevation versus abnormal albuminuria in the genesis and prediction of renal disease in diabetes. Diabetes Care 15: 1181-1204

17. Patel V, Rassam S, Newsom R, Wiek J, Kohner E (1992) Retinal blood flow in diabetic retinopathy. BMJ 305: 678683

18. Robinson F, Riva CE, Grunwald JE, Petrig BL, Sinclair SH (1986) Retinal blood flow autoregulation in response to an acute increase in blood pressure. Invest Ophthalmol Vis Sci 27: 722-726

19. Klein R, Klein BEK, Moss SE, Davis MD, DeMets DL (1989) Is blood pressure a predictor of the incidence of progression of diabetic retinopathy? Arch Intern Med 149: 2427-2432

20. Krolewski AS, Warram JH, Cupples A, Gorman CK, Szabo AJ, Christlieb AR (1985) Hypertension, orthostatic hypotension and the microvascular complications of diabetes. $J$ Chronic Dis 38: 319-326

21. Norgaard K, Feldt-Rasmussen B, Deckert T (1991) Is hypertension a major independent risk factor for retinopathy in type 1 diabetes? Diabet Med 8: 334-337 